\title{
НОВЫЕ ВОЗМОЖНОСТИ КОМПЛЕКСНОГО ЛЕЧЕНИЯ ПАЦИЕНТОВ С ХРОНИЧЕСКИМ ЛОКАЛИЗОВАННЫМ ПАРОДОНТИТОМ СРЕДНЕЙ СТЕПЕНИ ТЯЖЕСТИ
}

\section{NEW POSSIBILITIES OF COMPREHENSIVE TREATMENT OF PATIENTS WITH MEDIUM CHRONIC LOCALIZED PERIODONTITIS}

I. Sinev

Summary. The article presents the author's method of patients' rehabilitation with chronic localized periodontitis of moderate severity in the lower jaw. The aim- to improve the treatment of patients with chronic localized periodontitis of moderate severity in the lower jaw using a modernized fixed splint design. Comprehensive diagnosis and treatment of 25 patients aged 35 to 58 years were carried out. The examination included an assessment of the dental and periodontal status. The inflammation degree of the periodontal tissues was researched using the Müllemann-Cowell index. We used the Miller scale in the Flezar modification to study the degree of tooth mobility. We also used $X$-ray research methods, namely, orthopantomography, enlargement radiography and computed tomography of the lower jaw. Periotestometry and occlusiography were also carried out. The use of the proposed method of teeth splinting makes it possible to achieve immobilization of movable teeth, to prevent the development of periodontitis of moderate severity and possible complications.

Keywords: comprehensive treatment, periodontitis, teeth splinting, destruction of the tooth crown, post-and-core inlay.

\section{Введение}

$\Pi$ о различным данным, на сегодняшний день заболевания пародонта, а именно пародонтиты встречаются у 70-80\% взрослого населения [1,2]. Причем, распространенность этой патологии с каждым годом растет и вызывает все большую озабоченность со стороны врачебного сообщества. Причины возникновения пародонтита можно разделить на две группы: общие и местные. К общим относятся соматическая патология, стрессы и несостоятельность факторов иммунной защиты. К местным причинам можно отнести нарушения равновесия между бактериальной составляющей и тканями полости рта, так же нависающие края пломб и неудовлетворительное состояние ортопедических стоматологических конструкций [3].
Синев Илья Игоревич

Аспирант, ФГБОУ ВО «Самарский государственный медицинский университет» Минздрава России

ilya-sinev@yandex.ru

Аннотация. В статье представлена авторская методика лечения пациентов с хроническим локализованным пародонтитом средней степени тяжести на нижней челюсти. Цель- совершенствование лечения пациентов с хроническим локализованным пародонтитом средней степени тяжести на нижней челюсти использованием модернизированной конструкции несъемной шины. Проведены комплексная диагностика и лечение 25 пациентов в в0зрасте от 35 до 58 лет. Обследование включало в себя оценку стоматологического и пародонтального статуса. Степень воспаления тканей пародонта исследовали с помощью индекса Мюллемана-Коуэлла. Применяли шкалу Miller в модификации Flezar для изучения степени подвижности зубов. Так же использовали рентгенологические методы исследования, а именно ортопантомографию, прицельную рентгенографию и компьютерную томографию нижней челюсти. Кроме того, проводились периотестометрия и окклюзиография. Применение предлагаемого способа шинирования зубов позволяет добиться иммобилизации подвижных зубов, стабилизировать дальнейшее развитие пародонтита и предупредить возможные осложнения.

Ключевые слова: комплексное лечение, пародонтит, шинирование зубов, отсутствие клинической коронки зуба, культевая штифтовая вкладка.

Лечение данного заболевания всегда должно быть комплексным [4,5]. Одним из методов ортопедического лечения является шинирование подвижных зубов и восстановление целостности зубных рядов [6-8].

\section{Цель работы}

Совершенствование лечения пациентов с хроническим локализованным пародонтитом средней степени тяжести на нижней челюсти использованием модернизированной конструкции несъемной шины.

\section{Материалы и методы исслеАования}

Модернизация конструкции шины заключается в следующем (Патент РФ на полезную модель № 175754 
от 18.12.2018) [9]. Шина для устранения подвижности зубов содержит цельнолитой металлический каркас со штифтами для фиксации в корневых каналах зубов. Металлический каркас изготовлен в виде цельнолитой балки со штифтами, при этом для депульпированных зубов с параллельными каналами длина корневых штифтов составляет 2/3 длины каналов корней зубов, а для зубов с непараллельными каналами или при невозможности достаточной распломбировки корневых каналов длина штифтов составляет до 1/3 длины каналов и являются параллельными между собой и всеми каналами депульпированных зубов. Шина обеспечена парными парапульпарными штифтами длиной до 2-2.5 мм, которые параллельны между собой и с остальными штифтами, для фиксации шины на живых зубах. Видимая часть цельнолитой шины на шинируемых зубах покрыта слоем керамики под цвет последних.

Область применения шины для устранения подвижности зубов - полноценные зубные ряды верхней и нижней челюстей, зубные ряды с отсутствующим зубом (зубами) в переднем и боковом отделах до моляров.

В качестве опорного зуба с отсутствующей клинической коронкой предложено «Устройство для восстановления отсутствующей клинической коронки премоляров и передних зубов» (Патент РФ на полезную модель № 197641 от 19.05.2020) [10]. Оно содержит цельнометаллическую штифтовую вкладку с покрывной конструкцией, штифтовая вкладка покрыта керамикой необходимой толщины с восстановлением формы, размера и цвета отсутствующей естественной клинической коронки. Устройство состоит из металлической цельнолитой культевой штифтовой вкладки, которая представлена штифтом для фиксации в канале корня зуба, и искусственной культи, покрытой обожженной керамикой, при этом толщина керамического слоя не должна превышать 2 мм, в противном случае возможен ее скол.

Преимущества шины для устранения подвижности зубов - уменьшение объема препарирования здоровых тканей зубов для создания паза, при этом балка изготавливается с учетом индивидуальных особенностей анатомии клинических коронок. Имеется возможность наложения шины при расхождении каналов шинируемых зубов. Кроме этого, возможно сохранять отдельные зубы живыми, сделать шину эстетичнее за счет керамического покрытия. Конструкционная особенность шины заключается в ее применении при отсутствии одного или нескольких зубов, и возможностью использовать премоляры в качестве опорных элементов.

Преимущества устройства для восстановления отсутствующей клинической коронки премоляров и передних зубов- расширение показаний для несъемного протезирования, обеспечение надежной фиксации устройства, сокращение сроков протезирования за счет уменьшения количества клинико-лабораторных этапов.

Лечение с помощью шинирующей конструкции, у которой в качестве опоры мостовидного протеза использовали устройство для восстановления отсутствующей клинической коронки премоляров и передних зубов, провели у 25 пациентов, из них 11 мужчин и 14 женщин в возрасте от 35 до 58 лет. По данной методике протезировано 12 отдельно стоящих зубов с отсутствующими клиническими коронками, а в качестве опоры в шинах использовано 8 однокорневых зубов с отсутствующими клиническими коронками. Состояние после шинирования было удовлетворительным у всех пациентов. Осложнений после вмешательства не наблюдалось. Через 1 месяц после проведения процедуры шинирования у больных уменьшилась патологическая подвижность зубов и глубина пародонтальных карманов, отсутствовали жалобы на ухудшение качества жизни и затруднения гигиены полости рта, но определялось незначительное отложение зубного налета. При рентгенологическом исследовании нижней челюсти через 6 месяцев у пациентов наблюдалось уменьшение глубины костных карманов, нормализация костного рисунка.

Клиническое обследование пациентов с хроническим локализованным пародонтитом средней степени тяжести на нижней челюсти осуществляли комплексно. Оценивали стоматологический и пародонтальный анамнезы, степень воспаления тканей пародонта, основным признаком которого является кровоточивость, оценивали с помощью индекса Мюллемана-Коуэлла, так же изучали характеристику анатомо-топографических особенностей тканей пародонта. Степень подвижности зубов изучали по шкале Miller в модификации Flezar [11]. Дополнительными методами исследования являлись рентгенологические, а именно ортопантомография, прицельная рентгенография и компьютерная томография нижней челюсти, выполненные на аппарате Kodak 9000 <3D Extraoral Imaging System (Франция) [12]. С их помощью производили оценку размеров корней зубов, состояние периапикальных тканей, наличие и степень резорбции и атрофии костных стенок альвеолы. Так же проводилась периотестометрия и окклюзиография. Оценивали состояние периодонта, опорно-удерживающего аппарата зубов, с помощью аппарата «Периотест - C» (Periotest S, фирма «Сименс», Германия) до лечения, после наложения шины, через 1 и 6 месяц после проведенного лечения. Каждому пациенту проводили окклюзиографию- метод выявления и регистрации окклюзионных контактов при помощи артикуляционной бумаги. 


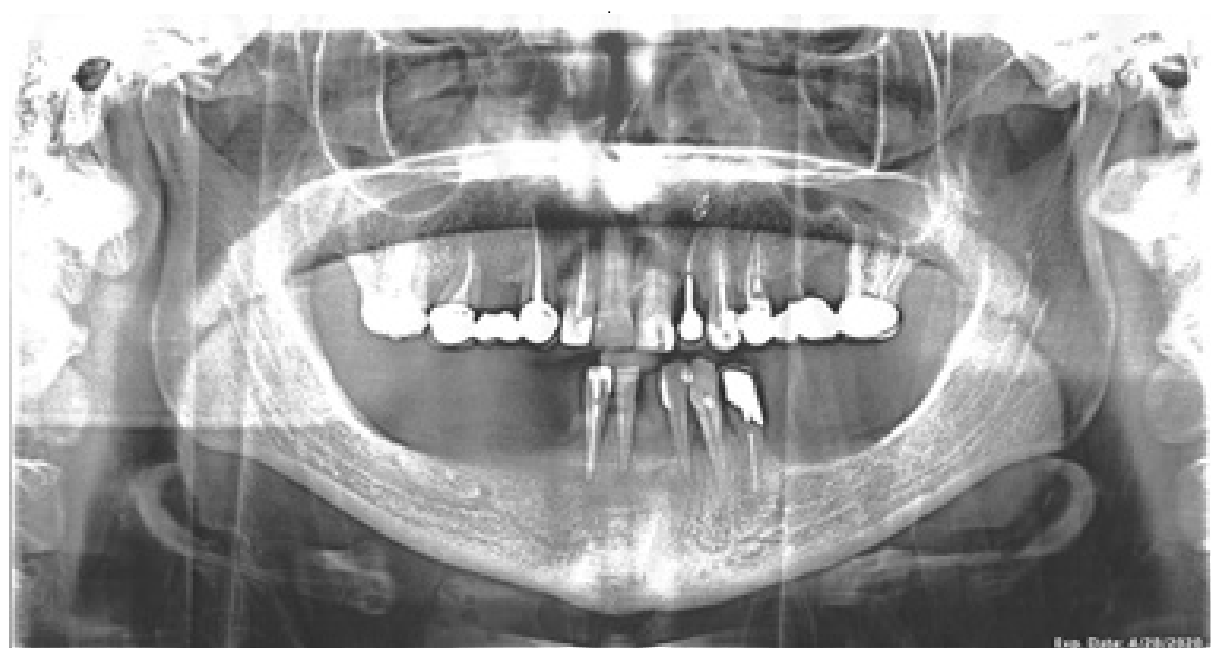

Рис. 1. Фото ортопантомограммы пациентки С., 45 лет

Статистическую обработку полученных данных проводили с использованием пакетов программ IBM SPSS Statics 25 PS iMAGO-5.0, лицензия № 5725-A54.

Клинический случай совместного применения шины для устранения подвижности зубов (Патент РФ № 175754) и устройства для восстановления отсутствующей клинической коронки премоляров и передних зубов (Патент РФ № 197641).

Исследование было выполнено в соответствии со стандартами надлежащей клинической практики (Good Clinical Practice) и принципами Хельсинской Декларации. Протокол исследования был одобрен Этическими комитетами всех участвующих клинических центров. До включения в исследование у всех участников было получено письменное информированное соглаcиe.

В клинику обратилась пациентка (С., 45 лет) с жалобами на затрудненное пережевывание пищи, отсутствие зубов, подвижность и кровоточивость зубов нижней челюсти 3.3, 3.2, 4.1, 4.2 (рис. 1).

При объективном осмотре была выявлена 2 степень подвижности по Флезару у зубов 3.2; 4.1 и 1 степень подвижности у зубов 3.3 и 4.2. А также неудовлетворительное состояние металлокерамической коронки на зубе 3.4. Для оценки степени воспаления тканей пародонта, а именно кровоточивости, использовали индекс Мюллемана-Коуэлла, который был равен 2,5 балла.

При рентгенологическом исследовании зубов 3.3, 3.2, 4.1, 4.2 определялась убыль костной ткани межзубных перегородок, вертикальная резорбция межзубных альвеолярных перегородок, костные карманы и расши- рение периодонтальной щели. Анализ периотестометрии у пациентки C., 45 лет до начала лечения составил 21,9 y.e.

Пациентке С., 45 лет поставлен диагноз: частичное отсутствие зубов на нижней челюсти I класс по Кеннеди, хронический локализованный пародонтит средней степени тяжести.

Пациентке назначено комплексное лечение, а именно терапевтическое (эндодонтическое) лечение зубов 3.3, 3.2, 4.1, 4.2, ортопедическое лечение - снятие металлокерамической коронки, последующее долговременное шинирование и восстановление целостности зубных рядов.

Корневые каналы зубов 3.4, 3.3, 4.1, 4.2 параллельны между собой, поэтому были распломбированы на 2/3 их длины. Корневой канал зуба 3.2 дивергирует относительно осей всех имеющих зубов, которые будут объединены шинирующей конструкцией, поэтому он распломбирован на 1/3 длины корневого канала. Далее с язычной поверхности зубов 3.3, 3.2, 4.1, 4.2 был отпрепарирован паз (1) с учетом расположения устьев (2) корневых каналов, а уступ зуба 3.4 был отпрепарирован под углом $90^{\circ}$ (3) ниже уровня десны относительно его продольной оси (рис. 2).

Далее мы получали одноэтапный двухслойный оттиск силиконовой массой Speedex с использованием беззольных штифтов. В лаборатории изготовили рабочую модель из супергипса. Зубным техником были смоделированы внутриканальные штифты, каркас будущей шины, содержащей искусственный литой зуб и металлическую часть штифтового зуба. Техник оставлял место для нанесения слоя керамики 0,8-0,9 мм от наружной поверхности балки до верхней границы препарирован- 


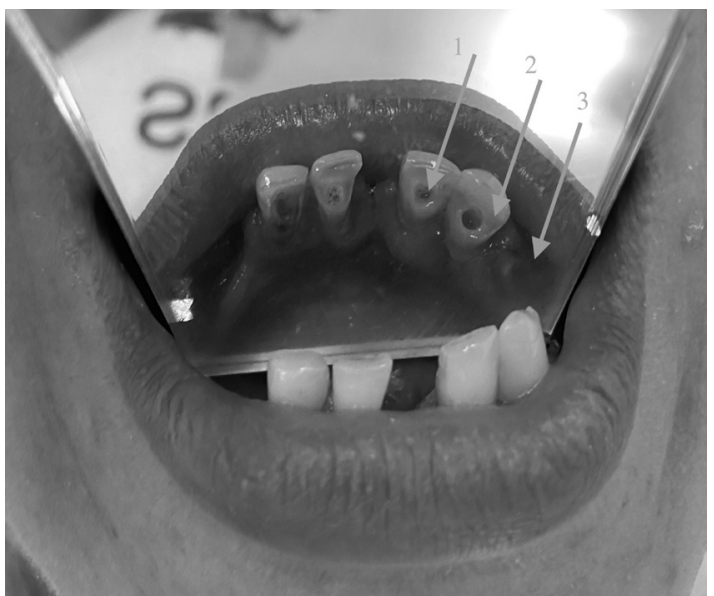

Рис. 2. Вид зубов после препарирования под шину пациентки С., 45 лет (зеркальное изображение): 1- устье корневого канала; 2- отпрепарированный паз; 3- надкорневая часть зуба 3.4 .

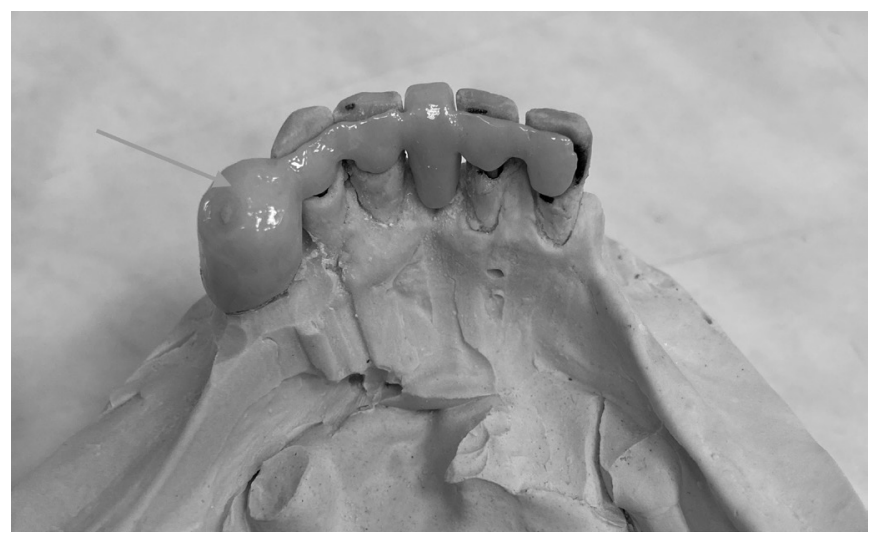

Рис. 4. Оральная поверхность готовой шины на гипсовой модели. Штифтовый зуб нашей конструкции.

ного паза и зубов антагонистов. Для изготовления конструкции использовали кобальхромовый сплав.

Далее припасовали шину на гипсовой модели и в полости рта и определили цвет керамики с использованием шкалы Vita (рис. 3).

Длина корневых штифтов 2/3 в параллельных корневых каналах и длина штифтов 1/3 в непараллельном канале обеспечили беспрепятственное наложение шины. Нанесли керамическое покрытие, соответствующее цвету и анатомической форме зубов, на поверхность металлической балки с язычной стороны, так же на литой каркас отсутствующего зуба и коронковой части штифтового зуба (рис. 4,5).

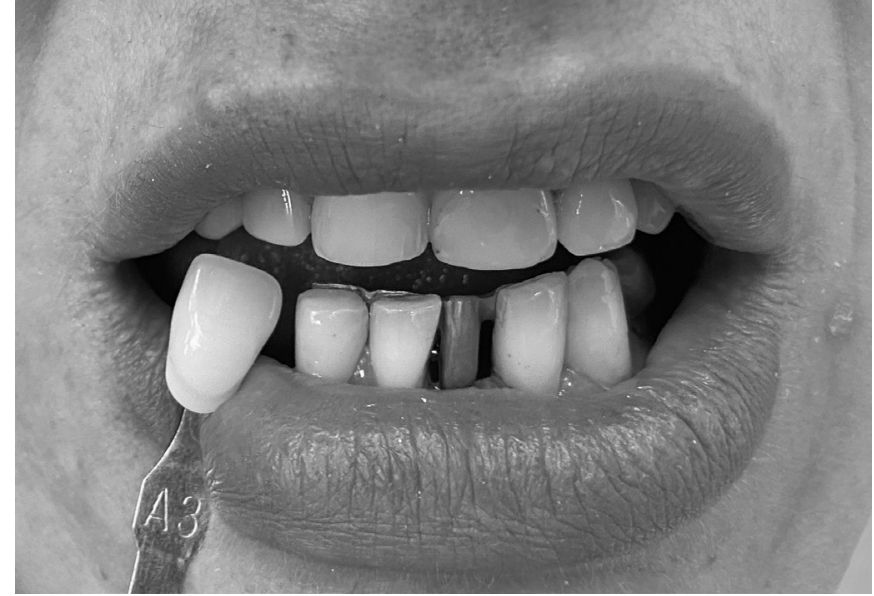

Рис. 3. Припасовка шины с отсутствующим центральным зубов в полости рта. Определение цвета керамики с использованием шкалы Vita.

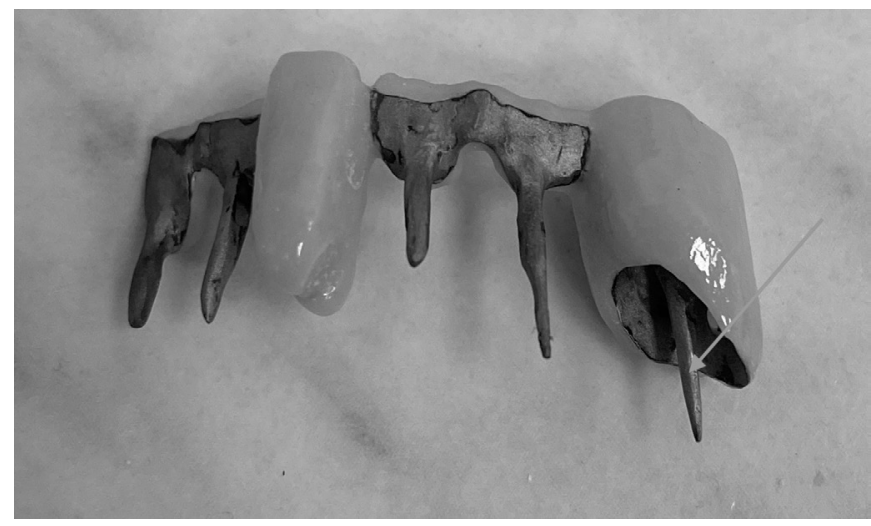

Рис. 5. Вестибулярная поверхность готовой шины пациентки С., 45 лет.

После этого произвели припасовку готовой цельнолитой шины в полости рта и фиксацию стеклоиономерным цементом GC Fuji I.

До и после фиксации шины провели окклюзиографию при помощи артикуляционной бумаги для выявления преждевременных контактов. Для восстановления целостности зубных рядов пациентке С., 45 лет изготовили частичный съемный термопластический протез из материала Perflex Biosense (рис. 6).

\section{Результаты и обсужления}

При использовании предложенной нами конструкции шины для устранения подвижности зубов сводит- 


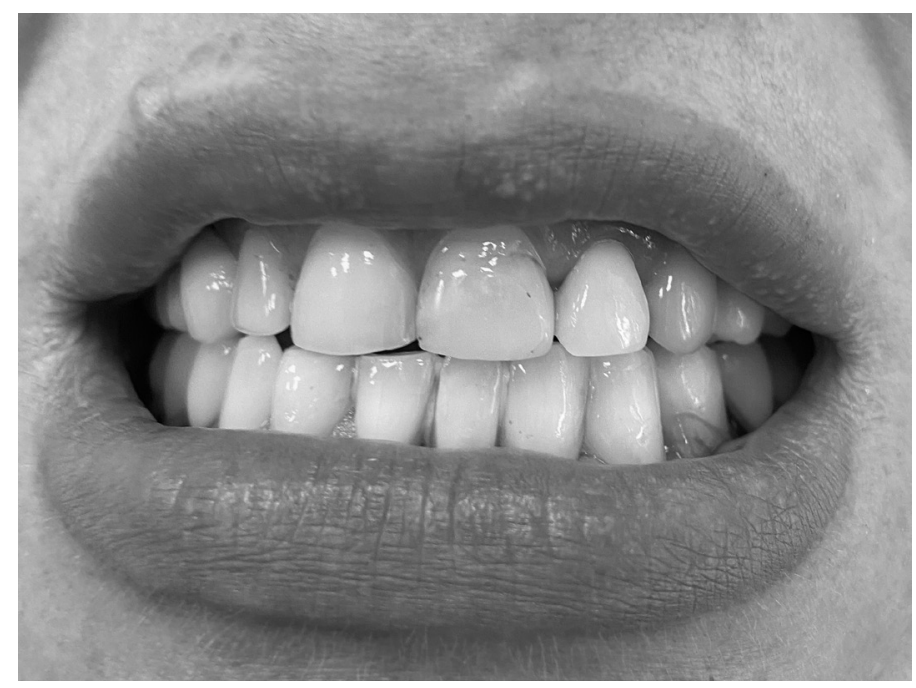

Рис. 6. Вид шины в полости рта после её фиксации и наложения частичного съемного термопластического протеза. Фото передних зубов пациентки С., 45 лет

ся на нет дополнительное сошлифовывание здоровых тканей зубов, обеспечивается надежное соединение как передней, так и боковой групп зубов даже при дивергенции корневых каналов. Имеется возможность применить предложенную шину при отсутствии одного зуба либо при наличии сильно разрушенного зуба, как в передней, так в боковой группах зубов. Эстетический эффект шины достигнут наличием керамического покрытия.

Использование устройства для восстановления отсутствующей коронки премоляров и передних зубов позволяет устранить полный дефект коронки зуба, восстановить клиническую коронку зуба за короткий срок и использовать в качестве опорного элемента мостовидных протезов. Данная конструкция удовлетворяет эстетические требования пациентов за счет керамической облицовки металлического каркаса.

После проведенного комплексного лечения 25 пациентов состояние шинирующих конструкций и штифтовых зубов (12 отдельностоящих штифтовых зубов и 8 однокорневых штифтовых зубов в конструкциях шин.) было удовлетворительным. У всех пациентов отсутствовали жалобы на подвижность зубов, болевые ощущения при чистке зубов и приеме пищи, восстановилась жевательная функция. Кроме того, пациенты не ощущали дискомфорта от присутствия конструкций на зубах, отмечали внешнее улучшение состояния десны, отсутствие признаков воспаления и галитоза.

Результаты исследуемых показателей в сроки 1 и 6 месяцев: кровоточивость по индексу Мюллемана-Коу-

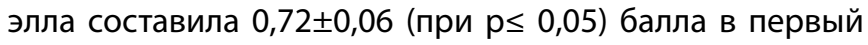
месяц после лечения, а через 6 месяц после наложения

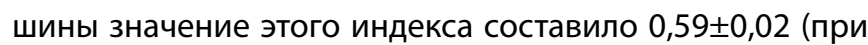
$\mathrm{p} \leq 0,05)$ балла, что свидетельствует о повышении мотивации пациента к проведению гигиены, из-за благоприятной картины в первые месяцы лечения.

Средние показатели подвижности зубов по шкале Miller-Fleszar составили 0,49 $\pm 0,04$ (при р $\leq 0,05$ ) ед. в пер-

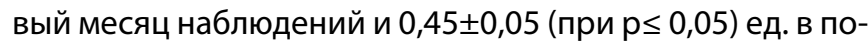
следующие полгода. На основании этих значений можно сделать вывод о стабилизации процесса деструкции и началу формирования новых здоровых клеток кости. В подтверждение этому проведен анализ специальных методов исследования.

Результаты до наложения шины у всех пациентов составляли $24,27 \pm 0,38$ (при $\mathrm{p} \leq 0,05$ ) у.е. Анализ данных периотестометрии показал снижение значений в 3-4

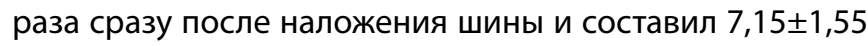
(при $\mathrm{p} \leq 0,05)$ у.е. что уже находится в пределах нормы. Через 1 месяц после шинирования значения были рав-

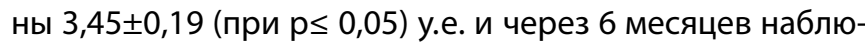
далось снижение показателей до 2,22 20,26 (при $\mathrm{p} \leq 0,05$ ) y.e.

По данным прицельной рентгенографии в первый месяц после фиксации шины наблюдалось отсутствие очагов хронического периодонтита, костная ткань имела четкий мелкоячеистый рисунок, выявлено уменьшение размеров периодонтальной щели, а также очагов остеопороза. Через 6 месяцев после шинирования произошло уменьшение размеров костных карманов. Отмечено исчезновение активности в зонах деструкций и возобновление репаративных процессов. 


\section{Зак^ючение}

Таким образом, анализ результатов комплексного лечения 25 пациентов с хроническим локализованным пародонтитом средней степени тяжести на нижней челюсти с использованием литой шины с керамическим покрытием позволил установить, что данный метод является щадящим способом иммобилизации подвижных зубов. Предупреждает дальнейшее развитие заболевания, уменьшает размеры патологических карманов, что способствует полноценной реабилитации больных с хроническим локализованным пародонтитом средней степени тяжести. Кроме этого, предложенный нами метод для восстановления отсутствующей клинической коронки премоляров и передних зубов позволяет использовать зубы с отсутствующими клиническими коронками как самостоятельные конструкции, так и опорные элементы шинирующей конструкции. Исходя из полученных результатов можно сделать вывод о благоприятном прогнозе для клинического применения литой шины с керамическим покрытием в лечении пациентом с хроническим локализованным пародонтитом средней степени тяжести на нижней челюсти.

\section{ЛИТЕРАТУРА}

1. Баймиев Ал.Х., Швец К. Ю., Мавзютов А. Р., Тамарова Э. Р., Булгакова А. И. Количественный анализ микробиоты пародонтальных карманов и слюны методом ПЦР в режиме реального времени до и после лечения пародонтита.—- Молекулярная генетика, микробиология и вирусология.—2017; 35(3): 103-108. Doi 10.18821/0208-0613-2017-35-3-103-108.

2. Микляев С.В., Леонова 0. М., Сущенко А. В. Анализ распространенности хронических воспалительных заболеваний тканей пародонта //Современные проблемы науки и образования.-2018; 2: 15.

3. Wang L, Xie X, Qi M, Weir MD, Reynolds MA, Li C, Zhou C, Xu HHK. Effects of single species versus multispecies periodontal biofilms on the antibacterial efficacy of a novel bioactive Class-V nanocomposite.—Dent Mater. — 2019 Jun; 35(6): 847-861. pii: S0109-5641(18)31354-X. doi: 10.1016/j.dental.2019.02.030.

4. Асташина Н.Б., Казаков С. В., Рогожникова Е. П., Горячев П. С. Разработка неинвазивной шинирующей конструкции как лечебно-профилактического аппарата, используемого при лечении пациентов с хроническим генерализованным пародонтитом// Проблемы стоматологии. — 2018. — т. 14, № 1, стр. $52-56$.

5. Макеев Г.А., Авсянкин А. В., Бутук Д. В., Яворская Л. В. Сравнительная характеристика методов шинирования подвижных зубов при лечении заболеваний пародонтита, осложненное дефектами зубных рядов.- Актуальные вопросы стоматологии. Сборник научных трудов, посвященный основателю кафедры ортопедической стоматологии КГМУ профессору Исааку Михайловичу Оксману. -Казань,2018. — С. 231-235.

6. Наумович С.А. и др. Методы ортопедического лечения заболеваний периодонта. / Учебно-методическое пособие. - 3-е изд., перераб. и доп. Минск: БГМУ, 2018. - 92 c.

7. Artzi Z., et al. Regeneration of the Periodontal Apparatus in Aggressive Periodontitis Patients. — Dent J (Basel). 2019 Mar 8;7(1): 29. doi: 10.3390/dj7010029.

8. Mazurova K. et al. Gingival recession in mandibular incisors and symphysis morphology-a retrospective cohort study. — Eur J Orthod. 2018 Apr 6;40(2):185-192. doi: 10.1093/ejo/cjx046.

9. Шина для устранения подвижности зубов: пат. 175754 Рос. Федерация: МПК А61С 13/00 (2006.01) М. И. Садыков, А. М. Нестеров, С. В. Винник, И. И. Синев, В. В. Карташов, М. Р. Сагиров, Г. М. Нестеров; заявители и патентообладатели: М. И. Садыков, А. М. Нестеров, С. В. Винник, И. И. Синев, В. В. Карташов, М. Р. Сагиров, Г. М. Нестеров. № 2017114859; заявл. 26.04.2017; опубл. 18.12.2017, Бюл. № 35.— 5 С.

10. Устройство для восстановления отсутствующей клинической коронки премоляров и передних зубов: пат. 197641 Рос. Федерация: МПК Ф61С 13/00(2006.01) В. В. Матросов, А. М. Нестеров, М. И. Садыков, А.С. Скворцов, М. Б. Хайкин, И. И. Синев, Р. В. Дюдюкин; заявители и патентообладатели В. В. Матросов, А. М. Нестеров, М. И. Садыков, А. С. Скворцов, М. Б. Хайкин, И. И. Синев, Р. В. Дюдюкин. № 2019143931; заявл. 23.12.2019; 0публ. 19.05.2020, Бюл. № 14-5 С.

11. Петров Ю.В., Ткач Т. М., Меленберг Т. В., Садыков М. И. Клиника, диагностика, лечение пародонтита: Учебное пособие.—Самара; СамГМУ, $2005 ;$ - 216 с.

12. Тамасханова М. И. Клинико-рентгенологическая оценка состояния костной ткани при воспалительных заболеваниях пародонта: дис. ... канд. мед. наук: 14.01.14 / Тамасханова Марина Иссаевна.—- М., 2014. - 158 с.

(с) Синев Илья Игоревич ( ilya-sinev@yandex.ru).

Журнал «Современная наука: актуальные проблемы теории и практики» 